\title{
Article
}

\section{Disaster Management in Smart Cities}

\author{
Luís B. Elvas ${ }^{1,2}{ }^{(}$, Bruno Miguel Mataloto ${ }^{1} \mathbb{D}$, Ana Lúcia Martins ${ }^{3}\left(\mathbb{D}\right.$ and João C. Ferreira ${ }^{1,2,4, * \mathbb{C}}$ \\ 1 ISTAR, ISCTE-Instituto Universitário de Lisboa, 1649-026 Lisboa, Portugal; \\ Luis_Manuel_Elvas@iscte-iul.pt (L.B.E.); Bruno_Mataloto@iscte-iul.pt (B.M.M.) \\ 2 Inov Inesc Inovação-Instituto de Novas Tecnologias, 1000-029 Lisbon, Portugal \\ 3 Business Research Unit (BRU-IUL), Iscte-Instituto Universitário de Lisboa, 1649-026 Lisbon, Portugal; \\ almartins@iscte-iul.pt \\ 4 Tecmic-Tecnologias de Microelectrónica, S.A., 2745-384 Queluz, Portugal \\ * Correspondence: joao.carlos.ferreira@iscte-iul.pt
}

check for updates

Citation: Elvas, L.B.; Mataloto, B.M.; Martins, A.L.; Ferreira, J.C. Disaster Management in Smart Cities. Smart Cities 2021, 4, 819-839. https:// doi.org/10.3390/smartcities4020042

Academic Editor: Pierluigi Siano

Received: 9 April 2021

Accepted: 17 May 2021

Published: 19 May 2021

Publisher's Note: MDPI stays neutral with regard to jurisdictional claims in published maps and institutional affiliations.

Copyright: (c) 2021 by the authors. Licensee MDPI, Basel, Switzerland. This article is an open access article distributed under the terms and conditions of the Creative Commons Attribution (CC BY) license (https:// creativecommons.org/licenses/by/ $4.0 /)$.

\begin{abstract}
The smart city concept, in which data from different systems are available, contains a multitude of critical infrastructures. This data availability opens new research opportunities in the study of the interdependency between those critical infrastructures and cascading effects solutions and focuses on the smart city as a network of critical infrastructures. This paper proposes an integrated resilience system linking interconnected critical infrastructures in a smart city to improve disaster resilience. A data-driven approach is considered, using artificial intelligence and methods to minimize cascading effects and the destruction of failing critical infrastructures and their components (at a city level). The proposed approach allows rapid recovery of infrastructures' service performance levels after disasters while keeping the coverage of the assessment of risks, prevention, detection, response, and mitigation of consequences. The proposed approach has the originality and the practical implication of providing a decision support system that handles the infrastructures that will support the city disaster management system-make the city prepare, adapt, absorb, respond, and recover from disasters by taking advantage of the interconnections between its various critical infrastructures to increase the overall resilience capacity. The city of Lisbon (Portugal) is used as a case to show the practical application of the approach.
\end{abstract}

Keywords: risk assessment; security; emergency systems; smart cities; disaster management; critical infrastructures

\section{Introduction}

Smart cities (SCs) and rapid urbanization are transforming the planet and the way we live: globally, around 3 million people move into the urban environment every week [1], and by 2050, cities are estimated to have additional 2.5 billion residents [1]. A greater concentration of people and assets can increase the number of disasters and their impact. According to the UN projections, $68 \%$ of the world's population will live in urban areas by 2050 [2]. As cities grow, municipalities invest in infrastructure and applications to improve citizens' operations, services, and the overall urban experience.

Living in a secure and resilient city with a smart city critical infrastructure (SCCI) means that citizens can feel secure in being provided with essential services without interruption, such as public transportation, communications, energy and water distribution, hospitals, and schools [3]. The critical infrastructures are, accordingly, gas stations, power plants, hospitals, transportation, banking and financial services, government offices, military facilities, water reservoirs, and bridges, among others. Disruptions in the operational continuity of the SCCI may result from natural or human-made (physical and/or cyberattacks) hazards on the network of interconnected systems. Recent reports and publications show an increase of combined physical and cyber-attacks that can imply relevant cascading effects on the SCCIs network due to interdependencies between critical infrastructures (CI) [4]. 
This shows that protecting and keeping the cities secure from failures in the continuity of its CI operation has become a task of enormous and increasing complexity, requiring the combination of multidisciplinary techniques and tools, the availability of very different skills (from security to maintenance, from communication to transport planning, from anthropology to social science, from energy network distribution to hospital service management, from IT to research and threats intelligence, etc.) [5], and the ability to correlate and explore large flows of data and information currently available from multiple sources, including social media [6]. Moreover, to protect a complex environment, such as the city, it is necessary to acknowledge the interrelations between the different types of CI and to develop tools and methods that are able to minimise cascading effects and allow rapid recovery of service performance levels after disruptions [7]. This is a central and fundamental aspect for protecting the urban environment liveability.

Smart cities are a combination of physical and IT systems and infrastructure, are able to secure social cohesion, and have the capacity to tackle and deploy innovation and improve cognitive capacities. These aspects are very much aligned with the emerging concept of resilience for cities, which is changing the paradigm of smart cities. Indeed, resilience sits in an intricate interplay among individuals, communities, institutions, and infrastructures [8]. We assume "resilience" in an urban perspective as a city's ability to succeed as a centre of human habitation, production, and cultural progress, despite the challenges posed by, e.g., climate change, population growth, and globalisation [9]. Cities are resilient if they absorb shocks, such as physical attacks, and are able to maintain their usual activity-of people, things, and services. As extensively addressed in literature, it is not appropriate to consider resilience as a single-disciplinary topic [9] but rather as a "concept" that is characterized by four main competencies: (1) Plan/Prepare; (2) Absorb; (3) Recover; and (4) Adapt. These competencies need to address four main socio-technical dimensions of every city: (1) physical; (2) information; (3) cognitive; and (4) social. Figure 1 shows examples of outcomes of each of the dimensions when crossing each of the competencies. It is possible to consider that resilience is a proactive approach to improve the capacity of infrastructures to prevent damage in advance of disturbance events, alleviate suffering during the disruptive events, and improve the recovery capability after the events, beyond the concept of pure prevention and hardening [10].

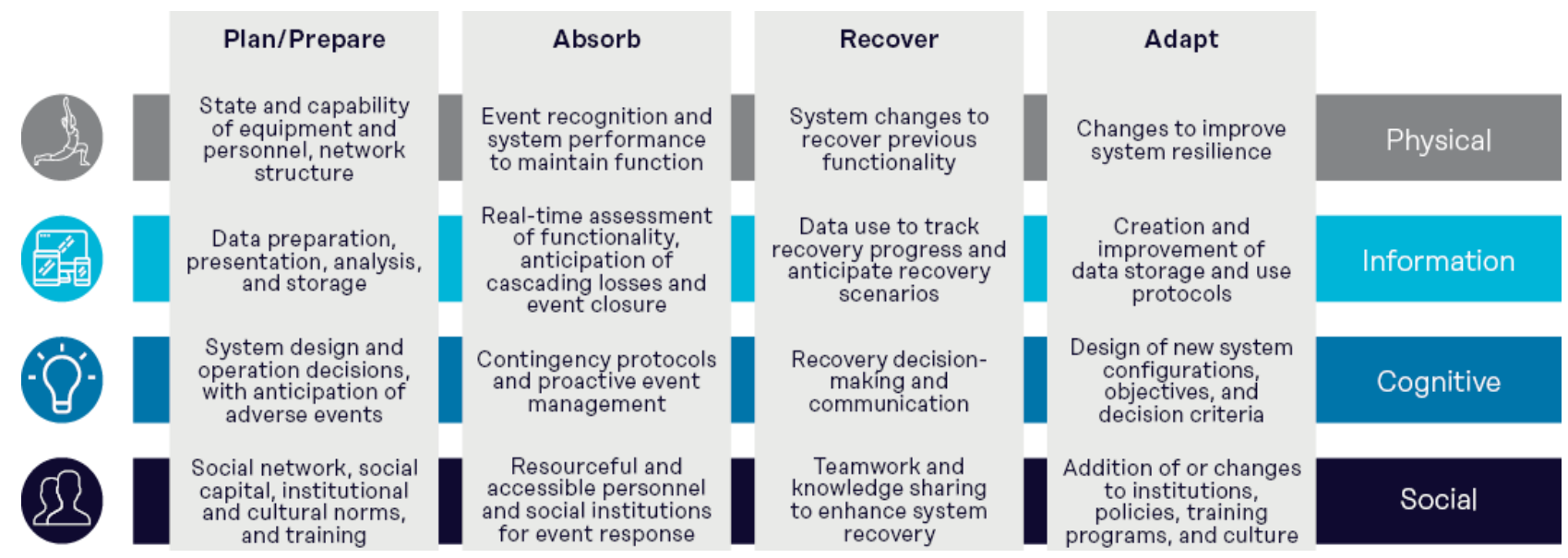

Figure 1. Operational resilience plans: example of the outcome.

The problem of resilience is being studied in several areas [11], and several domainspecific resilience definitions have been proposed by [12]. Among others, the definition provided by the resilience and policy committees of the National Academy of Sciences (NAS), which defined resilience as the ability of a system "to prepare and plan for, absorb, recover from, or more successfully adapt to actual or potential adverse events" [13], seems to be a very pragmatic one and very much in line with operational need. On the other 
hand, traditional approaches for risk management do not consider dependencies of events and associated cascading effects. Risk management contributes with a plan to handle adverse events, and resilience management goes several steps further by bringing together the temporal capacity of a system to absorb and recover from adverse events and adapt accordingly. Thus, resilience is a complementary attribute that uses adaptation and mitigation strategies to improve traditional risk management. Indeed, given a specific event, resilience can be seen as the link or the capability to link pre-hazards and post-hazards activities/phases moving from (1) risk assessment to (2) resilience characterization, to (3) countermeasures and mitigation actions, to (4) preparedness and planning, enabling a more effective response [14]. This means that existing and new smart systems, infrastructures, and services in an SCCI need to be able to fight hazards and absorb their impacts more efficiently and more effectively; accommodate and recover the effects of a hazard more efficiently, timely, and safely; and be designed/restored to coordinate more efficiently across the city's main competencies (Plan, Absorb, Recover, and Adapt) [14]. An example of operational resilience plans (ORPs) for SCCI is presented by [14].

Making the SCCI and its critical infrastructure components (CICs) smarter can be achieved by making the normal operation more adaptive, more intelligent, and more connected [15]. Current infrastructures become more complex when they are made smarter, making them more unstable and susceptible to cascading effects. The SCCI is exposed to disasters, such as physical ones or cyber-attacks. Protecting CICs and ensuring their continued operation will be an important part of future SCCI [16]. Therefore, it is essential to minimize CICs' destruction and the consequent cascading effects on the smart city; this could be achieved with a smart resilience approach. Figure 2 shows dependencies between some SCCIs and their connections and stakeholders. Data exchange between the different critical infrastructures in a smart city, if performed, which would be provided by the smart resilience approach, would allow, for instance, for information to find alternative paths to still reach its destination. The CIC's ability to anticipate, prepare for, adapt and withstand, respond to, and recover will influence the resilience of the SCCI.

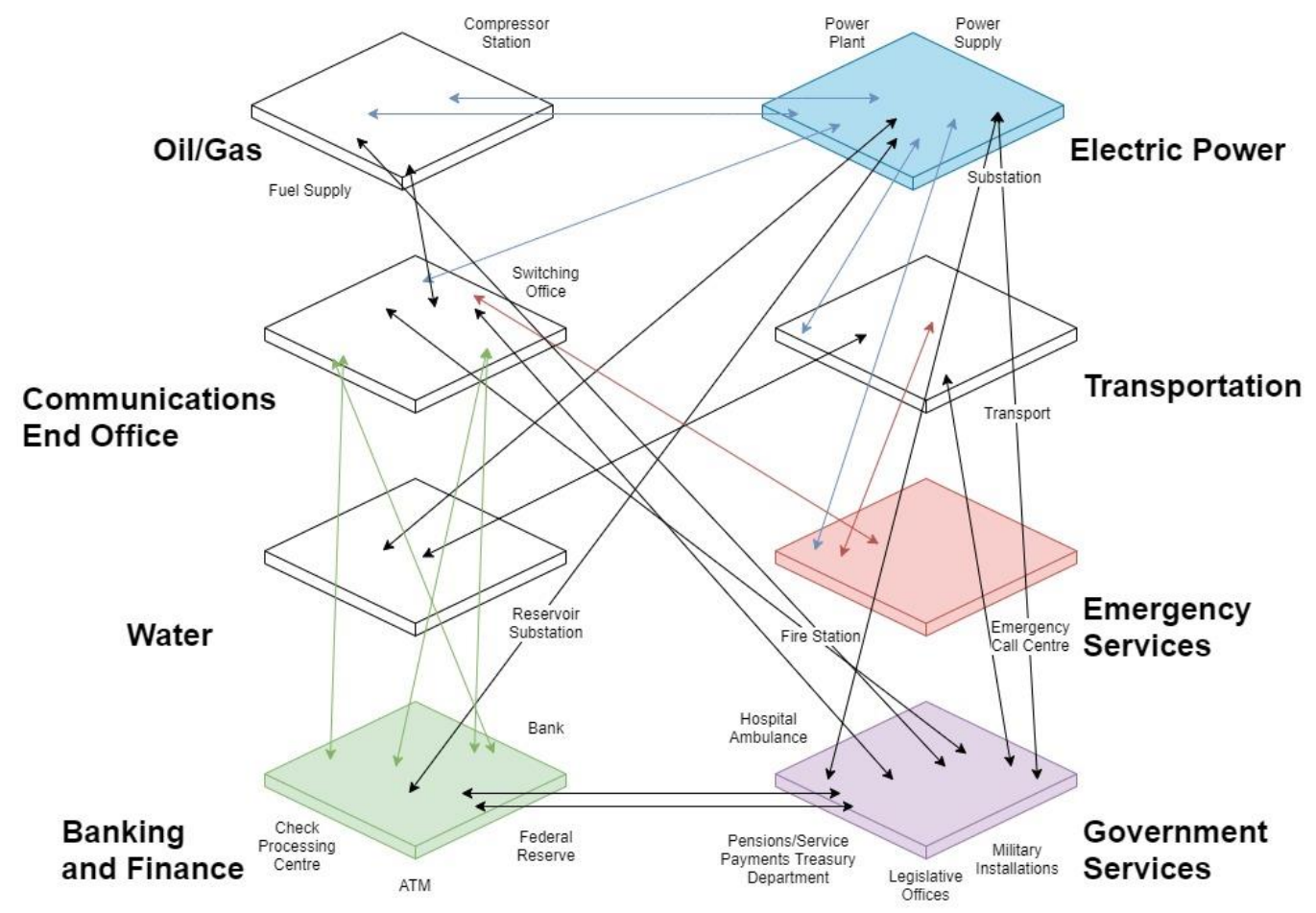

Figure 2. Dependencies between smart city critical infrastructures. 
Current response procedures rely on antiquated information sharing techniques and provide little or no opportunity to introduce change within the failing infrastructure systems [17]. There may also be low understanding of other important systems' components when one starts to fail. SCs, due to their dependency on data, need a system that allows them to be resilient to disasters and support disaster management. To the best of the authors' knowledge, there are not yet proposals to address the interconnected nature of the CIC.

Data exchange and data-driven approach contribute to Plan/Prepare, Absorb, Recover, and Adapt, for instance, fulfilled providing such resilience components as higher Reliability, Resistance/Robustness, and Redundancy, Rapidity, and Resourcefulness [18]. The system should also exploit interdependencies among critical infrastructures and smart systems: interdependencies can, on the one hand, facilitate the propagation of failure across coupled systems but, on the other hand, can generate additional flexibility in disruption conditions and additional resources that can promote the stable achievement conditions of the coupled system. The interdependencies should be developed/reviewed with stakeholders (within the supply chain), based on most likely scenarios, to strengthen the collective resilience of community supply and distribution systems [19].

With this research, we propose an integrated resilience system linking interconnected critical infrastructures in a smart city to improve disaster resilience. A data-driven approach is considered, using artificial intelligence and methods to minimize cascading effects and the destruction of failing critical infrastructures and their components (at a city level). This approach allows rapid recovery of infrastructures' service performance levels after disasters while keeping the coverage of the assessment of risks, prevention, detection, response, and mitigation of consequences. Overall, the research question pursued in this work is:

RQ: "How can smart cities' infrastructure be modelled to improve their resilience to physical disasters?"

A case is used to test our approach, the case of the city of Lisbon (capital of Portugal). In pursuing the aim of this work, the current disaster management system used in Lisbon is explored, and we propose a data-driven approach to improve the performance of incident management by understanding the main causes of these incidents. This approach will allow the mitigation of the impact of natural disasters in Lisbon by perceiving which areas are the most vulnerable and where the impact will be bigger. The variables with more significance on incidents are identified so that prevention units are available to respond to future incidents.

The research is organized as follows: Section 2 provides the conceptual foundation of the research, built from a systematic literature review perspective; Section 3 provides the proposed platform (SC4Forces); Section 4 provides the implementation details of the system; Section 5 details the simulation and prediction process towards crises scenario evolution; Section 7 shows the application of the system in the city of Lisbon, with the identification of areas that are more vulnerable to certain types of disasters, and the consequent cascading effects; Section 8 is dedicated to the discussion of the results; and Section 9 is the conclusion of the work.

\section{Systematic Literature Survey}

A systematic literature review was conducted to ground the development of the framework that will address this research's purpose and research question.

The systematic literature review was conducted following PRISMA (Preferred Reporting Items for Systematic Reviews and Meta-Analysis) methodology [20]. The research question that guided the search was: "What is the state of the art of infrastructure risks in smart cities?".

Scopus and Web of Science Core Collections were searched as databases, and the study was performed considering publications between 2016 and 31 December 2020. Only publications written in English were considered.

Selection of articles: The initial selection of papers was conducted based on the title and abstract of the study. The queries considered the "concept" being explored and the "target population". The keywords used and the screening items were as follows: 
for concept, the search was for "Modelling", since we wanted to address models other authors may have proposed on the topic; for the target population, the search was for "Infrastructure Risks" or "Infrastructure Interdependency", since these were the topics we wanted to study in terms of risk management; and within the context of the study, the keywords used were "Smart Cities" or "Network" or "Infrastructure", these being the topics in which our study was placed.

Data Extraction and synthesis: The data were managed and stored using Zotero and Microsoft Excel. The fields considered were title, author, year, journal, subject area, keywords, and abstract.

Conference papers and grey literature, such as seminars, novels, editorials, and duplicates, as well as works not relevant to the domain, were excluded. Only articles published in scientific journals were included. Although conference papers, or at least papers from some conferences, can be considered by some as highly prestigious, the opinion is not unanimous, and the criteria to select the papers and the conferences would be unclear. Consequently, all conference papers were excluded.

Duplicates were also removed from the analysis.

When the title and the abstract were considered insufficient to assess the fitting of the paper, the full document was analysed. Three researchers performed the screening process independently - every paper was screened by two of the researchers, and in case of disagreement a third one would decide.

Figure 3 shows the different steps and number of papers in each of them. Our search resulted initially in 36 documents. These 36 papers were analysed in detail. Three of the papers were not considered to be under the scope of the analysis and were therefore excluded.

Table 1 characterizes the 33 papers on the topics of their contents. Most of the papers focus on "infrastructure interdependency" and/or on "networks". It is possible to identify a lack of research papers on restoring/recovery, resilience, cascading failure, infrastructure risk, and cybersecurity. If the years are considered in the observation of the different topics on smart cities, "restring/recovery", "natural disasters", "infrastructure dependencies", "cascading effect", and "network" are receiving increased attention by researchers. It is also interesting to see that, leading to somewhat contradictory attention, "infrastructure risk" is receiving less attention while "network" and "infrastructure dependencies" are becoming more popular. This leads us to conclude that there is a gap in knowledge in smart cities research on how to approach disruption and disaster situations and that there is a need for contributions that can improve the resilience of smart cities.

Figure 4 shows a machine analysis of the keywords in the title and abstract of the 33 articles considered and their interconnections, exposing the papers' nature. It is possible to perceive that interdependency between systems is being actively studied, corroborating the content analysis shown in Table 1. Figure 4 also provides visibility on the interconnection between interdependencies analysis and resilience, disruption, and the infrastructure network in extreme events. The interdependencies are strongly associated with the analysis of systems and of critical infrastructures but very poorly associated with research on extreme events. Relations among different words provide useful information on hot topics and their relations.

Exploring the different papers in more detail, the survey [21] presented to us a critical analysis of methods and tools developed to assist with risk assessment and attack graph generation within large networked environments since current methods are unsatisfactory and fail in the identification of relationships and interdependencies between risks. Regarding hazards, study [22] identified critical locations and analysed their vulnerabilities using data. Researchers in [23] proposed a linear and nonlinear model capable of obtaining optimal solutions within a short time to optimise the maintenance planning of generic network-structured systems. Infrastructure systems are faced with a growing number of disruptions, and to address this issue, researchers in [24] quantified resilience with Bayesian networks to structure relationships among several variables, allowing the analysis of different resilience-building strategies. 
Table 1. Characterization of the 33 selected papers based on the main topics they approached.

\begin{tabular}{|c|c|c|c|c|c|c|c|c|c|c|}
\hline $\begin{array}{l}\text { Paper } \\
\text { [ref.] }\end{array}$ & Year & $\begin{array}{l}\text { Restore/ } \\
\text { Recovery }\end{array}$ & $\begin{array}{l}\text { Natural } \\
\text { Disasters }\end{array}$ & Resilience & $\begin{array}{c}\text { Infrastructure } \\
\text { Interdependency }\end{array}$ & $\begin{array}{c}\text { Interdependencies } \\
\text { (Others) }\end{array}$ & $\begin{array}{l}\text { Cascading } \\
\text { Failure }\end{array}$ & $\begin{array}{c}\text { Critical } \\
\text { Infrastructure }\end{array}$ & Network & $\begin{array}{c}\text { Infrastructure } \\
\text { Risk }\end{array}$ \\
\hline [21] & 2016 & & & & & $x$ & & & & $x$ \\
\hline [22] & 2016 & & & & $x$ & & & & & $x$ \\
\hline [23] & 2016 & & & $x$ & & & & & $x$ & \\
\hline [24] & 2016 & & $x$ & $x$ & & & & & $x$ & \\
\hline [25] & 2016 & & & & & $x$ & $x$ & $X$ & $x$ & \\
\hline [27] & 2017 & & & $x$ & $x$ & & $x$ & $x$ & & $x$ \\
\hline [28] & 2017 & & & & $x$ & & $x$ & $x$ & & \\
\hline [29] & 2017 & & & $x$ & & & & & $x$ & \\
\hline [30] & 2017 & & $x$ & & $x$ & & & $x$ & $x$ & \\
\hline [31] & 2018 & & & & $x$ & & & $x$ & & \\
\hline [32] & 2018 & & & & $x$ & & & & $x$ & \\
\hline [34] & 2018 & & & & $x$ & & & & $x$ & \\
\hline [35] & 2018 & & & & $x$ & & & & $x$ & \\
\hline [36] & 2019 & $x$ & & $x$ & $x$ & & & & & \\
\hline [37] & 2019 & & & & & & & & & $x$ \\
\hline [38] & 2019 & & $x$ & & $x$ & & & & & \\
\hline [39] & 2019 & $x$ & $x$ & & $x$ & & & $x$ & & \\
\hline [40] & 2019 & & & & & & & & & $x$ \\
\hline [41] & 2019 & & & & & & $x$ & & & $x$ \\
\hline [42] & 2019 & & & & & & & $X$ & $x$ & \\
\hline [43] & 2019 & & $x$ & & $X$ & & & $x$ & & \\
\hline [44] & 2020 & & & & & $x$ & & & $x$ & \\
\hline [45] & 2020 & & $x$ & & & & & $x$ & & \\
\hline
\end{tabular}


Table 1. Cont

\begin{tabular}{|c|c|c|c|c|c|c|c|c|c|c|}
\hline $\begin{array}{l}\text { Paper } \\
\text { [ref.] }\end{array}$ & Year & $\begin{array}{l}\text { Restore/ } \\
\text { Recovery }\end{array}$ & $\begin{array}{l}\text { Natural } \\
\text { Disasters }\end{array}$ & Resilience & $\begin{array}{l}\text { Infrastructure } \\
\text { Interdependency }\end{array}$ & $\begin{array}{c}\text { Interdependencies } \\
\text { (Others) }\end{array}$ & $\begin{array}{l}\text { Cascading } \\
\text { Failure }\end{array}$ & $\begin{array}{c}\text { Critical } \\
\text { Infrastructure }\end{array}$ & Network & $\begin{array}{c}\text { Infrastructure } \\
\text { Risk }\end{array}$ \\
\hline [46] & 2020 & $x$ & & $X$ & $x$ & & & & $x$ & \\
\hline [47] & 2020 & & & $x$ & $x$ & $x$ & $x$ & & $x$ & $x$ \\
\hline [48] & 2020 & & & & $x$ & & $x$ & & $x$ & \\
\hline [49] & 2020 & & & & $x$ & $x$ & & & $X$ & \\
\hline [50] & 2020 & & & $x$ & $x$ & & & & & \\
\hline [52] & 2020 & & $X$ & $X$ & $X$ & & & $X$ & $X$ & \\
\hline [53] & 2020 & & $X$ & & $X$ & & & & $x$ & \\
\hline \multicolumn{2}{|c|}{ Our work } & $x$ & $x$ & $x$ & $x$ & $x$ & & $x$ & $X$ & \\
\hline
\end{tabular}




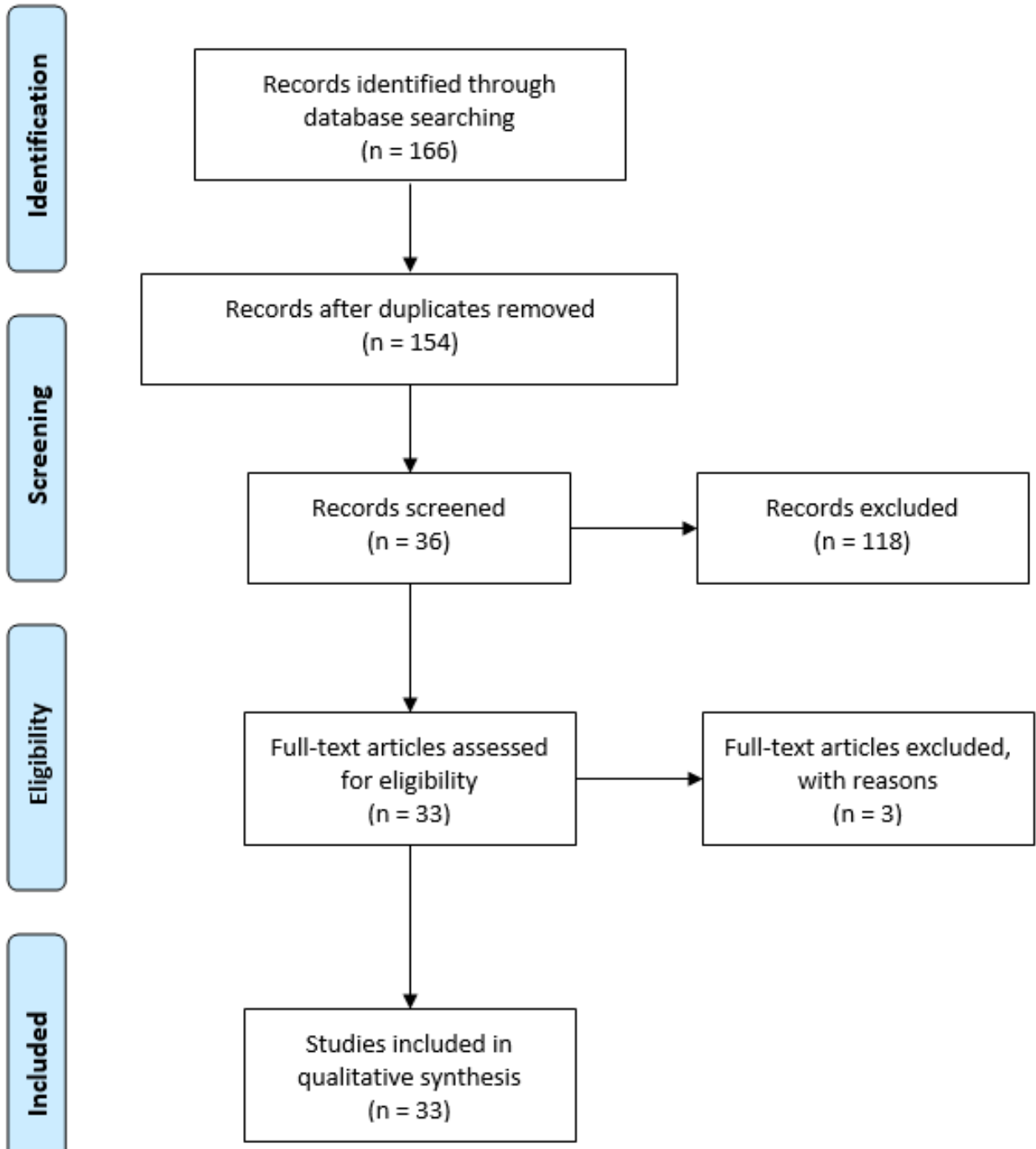

Figure 3. PRISMA workflow and the number of papers considered at each stage.

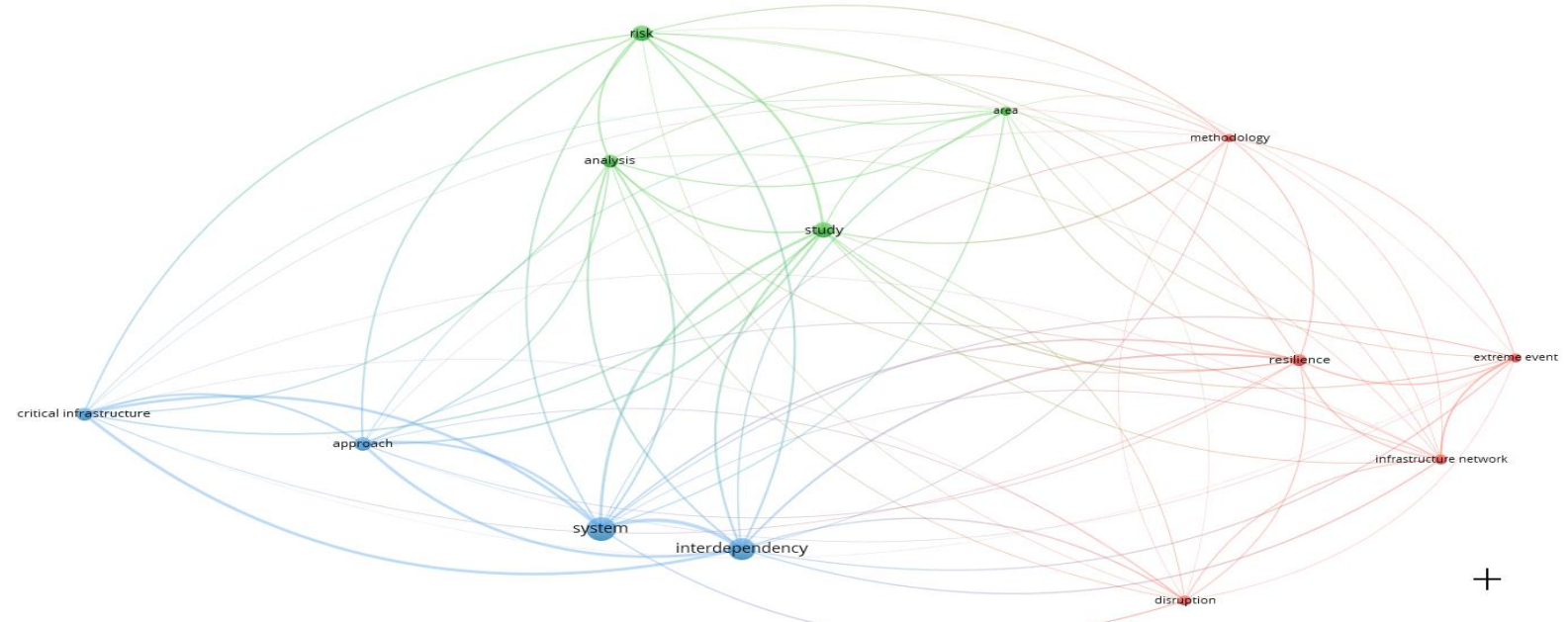

Figure 4. Proportion of times the words in the titles and abstracts from the 33 articles are used and the links between the use of those topics. 
In study [25], researchers proposed a system for assessing the availability of essential interdependent infrastructures subject to equipment failures, cascading errors from adjacent infrastructures, and natural disaster losses. In study [26], researchers intended to relate interdependencies and dependencies among infrastructures and how resilience affects recovery time and reduces adverse consequences among services when extreme weather events happen. Study [27] presented us with a methodology for preliminary interdependency analysis between critical infrastructures, and with this, it is possible to estimate any resilience, risk, or criticality measure an assessor might be interested in. Researchers in study [28] aimed to create a larger and more complex model that incorporates interdependencies by developing a modelling and simulation framework based on open hybrid automata. To quantify the resilience of a coupled traffic-power network under hazard scenarios, researchers in study [29] developed a bi-level, mixed-integer, stochastic program that shows the importance of considering interdependencies between critical infrastructures. In [30], the researcher proposed a new mathematical framework to model and analyse interdependencies of critical infrastructures. Researchers in study [31] reviewed the existing methods assessing critical systems security risk exposure, finding them insufficient to assess systems security risk exposure in the complexities associated with modern critical infrastructure systems. Another review was conducted by the authors of study [32], where the focus was on independency types and definitions of integrated infrastructures, where they arrived at the conclusion that modelling efforts are mainly on short-term operational purposes and extreme events, having the need for long-term efforts and having no consistency on the level of detail and type of integration. Since there is an estimated probability of $30 \%$ of an earthquake happening in the next 50 years in the Alpine fault, researchers in [33] tried to focus on an infrastructure-related economic disruption, where they advocated for an approach that evaluates consequences dynamically across space, through time, for multiple stakeholders in order to develop better economic value cases for resilience-related infrastructure investment. To better identify and understand interdependencies between infrastructure networks, researchers in [34] proposed a fuzzy modelling approach to address this identification and understanding. Once modern cities rely on interdependent infrastructures and disruptions often propagate through this infrastructure network, researchers in study [35] developed a model that will systematically investigate the mutual influence between the infrastructures and the communities in order to redistribute resources. In review [36], the authors addressed population displacement during natural disasters, offering guidelines for civil infrastructure system models assisting recovery managers and transportation system managers with reducing the length of time people are displaced. In [37], researchers provided important tools and insights for decision-makers on different actions to take to manage risks under uncertainty. Study [38] considered the services rendered by civil infrastructure to the efficiency of social infrastructure systems and the services they provide, and with this, it is possible to characterize a civil reconstruction with interdependent social infrastructure systems to maximize the reparation of damaged civil infrastructures. Attempting to address the recovery of dependent critical infrastructure systems, researchers in [39] explored the critical interfaces and interdependencies between these systems to develop an effective recovery plan. Since digitalization has a large emphasis, paper [40] stressed the potential challenges, consequences, threats, vulnerabilities, and risk management of data security to prevent data from getting into the wrong hands. Researchers in [41] aimed to enhance decision making before the design of an airport by performing a quantitative risk analysis focused on the annual fatality risk for airports and surrounding areas; this helped them to compute the annual projected number of fatality incidents for each point in the airport region. Since security incidents are increasing and represent a major threat to networks and formation systems, the authors of [42] applied a Markov chain model to assess critical national infrastructures' risk. To improve the investment options in preparedness, researchers in [43] developed a restoration map and a suite of infrastructure asset damage that will consider the infrastructure interdependencies. Study [44] concluded that a small number 
of methods have been proposed to model interdependencies among substations (S/Ss) in electric power systems. For this reason, the authors proposed a solution that offers a practical tool for decision-makers to distinguish between S/Ss and their mutual associations, which enables them to identify the critical S/Ss. In study [45], researchers aimed to find the critical infrastructures and the risk associated with compound flooding causes.

After an extreme event, it is necessary to define an action plan to recover from its effects. For this, in case of an extreme event, researchers in [46] proposed a combination of agent-based modelling and reinforcement learning to optimize the repairs and crew location after an extreme event to mitigate some of its impacts. In [47], authors studied the interdependency between infrastructures and their surrounding supply chain to model and assess these interdependencies. Study [48] tried to develop better decisions in the recovering process after a failure in a coupled system by studying its cascading effects when a small disturbance affects them. In [49], researchers aimed to analyse the network robustness under different failure scenarios by characterizing the impact on a network's interdependency. To consider the different classes of infrastructure dependencies, researchers in study [50] proposed a general mathematical formulation to account for these different classes by modelling the post-disaster recovery infrastructure while accounting for its dependencies. To model the infrastructure recovery, study [51] proposed the categorization of the infrastructure interdependencies into three levels based on the modelling resolutionsystem-to-system, system-to-facility, and facility-to-facility-which would improve the flexibility of the model and increase the accuracy of the modelling results. To minimize the impact of an extreme event on an infrastructure network, researchers in study [52] proposed a methodological framework for resource allocation that considers interdependencies among infrastructure systems. Study [53] analysed the impact of a natural disaster (seismic events) on a large-scale virtual city by modelling the interdependency between buildings and the electric distribution network. There is no data integration from existent systems and no commercial implementation as we are proposed in these papers.

\section{Method}

The development of the system was based on different steps, which are described next. Although the proposed solution required customization to each city in which it may be adopted, a case was used to test and illustrate some modules of the system.

The development of the system was composed of several steps, as follows:

(1) Conceptualization of the model.

a. This development level is firstly composed of the description of the data integration from different information systems. At this point, the original system is visited, and the specific challenges of a smart city are addressed;

b. Definition of the big picture of the central command centre and how it will coordinate the data that are available.

(2) Description of the implementation in a real scenario. At this point, several steps and corresponding tools are identified:

a. Data collection step, based on developed API for each system;

b. Data transmission step using API and TCP/IP communication with a central system;

c. Data integration step and ETL process developed in Python;

d. Data visualization step developed in Python;

e. Data analysis and management step developed in Python with Scikit-learn and TensorFlow;

f. Application and support services layer developed in Python.

(3) Simulation of predictive operations, with consequences in terms of prevention, mitigation, and resilience.

Due to the need to customize the system, some of the components were tested in a case, the city of Lisbon (capital of Portugal). This testing allowed us to identify the potential 
of the utilization of the proposed system, only based on historical data, and the impact on the prepositioning of resources and reduction of cascading effects.

\section{Smart City 4Forces Platform}

The proposal is oriented towards a holistic platform for an integrated approach of SCCI and its single CIs, which will emphasize handling incidents and cascading effects between SCCI's systems and infrastructures in a context of a smart city, where diversity of systems provides real-time data. This approach is enabled by a set of models and processes that address physical assets and criteria for handling disruptive processes.

Tecmic (www.tecmic.pt (accessed on 18.05.2021)) is a Portuguese company that, in collaboration with Inov (www.inov.pt (accessed on 18.05.2021)), has developed a disaster management system named 4Forces (https:/ /www.tecmic.com/en/tecmic-solutions/ emergency-and-public-safety / (accessed on 18.05.2021)). The 4Forces system is an emergency response technology that allows quick and efficient decision making in the face of "natural disasters, such as fires, floods, earthquakes, and chemical spills into the atmosphere or on land".

However, the system allowed the coordination of different public forces and the adjustment for smart cities with a high concentration and interdependency of critical infrastructures. The significant development was the data integration due to the different systems available. During 2020, this system was adapted to a smart city crises management (SC4Forces) platform that automatically generates incident reports in real-time, enabling correct decision making by relevant authorities, as well as available resources, together with tight management of the entire process, from planning to the smart allocation of means, following the prediction and analysis of threat evolution, as well as available resources. This adaptation was mainly performed through new data sources and data integration process. SC4Forces is the framework in this study for critical infrastructure (CI) operators (water, transport, health, and communication) and technology providers (industry and SMEs) to provide crisis data. All these entities provide data from their systems. Although the main development of the system is applicable to a wide variety of cases, its implementation will always have to be adjusted to the specific city as the critical infrastructures and the nature of the data each has available is different.

As a first step, data from different information systems had to be integrated. This was a hard task as it involved metadata information from the proprietary data systems of the different critical infrastructures. These metadata play a vital role in the integration process of large volumes of heterogeneous data. These data can be of low quality due to high data redundancy. The main concepts are shown in Figure 5, where data integration among different systems plays an important role. Once the information is integrated, the SC4Forces delivers a big picture to the central command. Additionally, an intervention resource, such as a fire brigade or ambulances, has the possibility to monitor and manage the crisis in real-time with route optimization. Figure 6 shows the main components of the central command platform. Several data interfaces were developed one for each of the different stakeholders that is involved in the city management such as the municipality, public transportation entities, water and electricity management entities, hospital and health providers, civil protection, fire brigades, and weather provider. These data are integrated, and the visualization process provides the command control with a big picture of the status of the disaster scenario. Machine learning algorithms provide predictions and a simulation scenario to assess the evolution. An interface with intervention sources provides information in real-time. We also added a chatbot for the city management entity to be able to interact with users (for details, see [54]). Interfaces for intervention forces are made available through mobile devices providing real-time data. This allows the command centre to check where the teams are located and improve the known position and operation movements towards a more coordinated disaster operation management. 


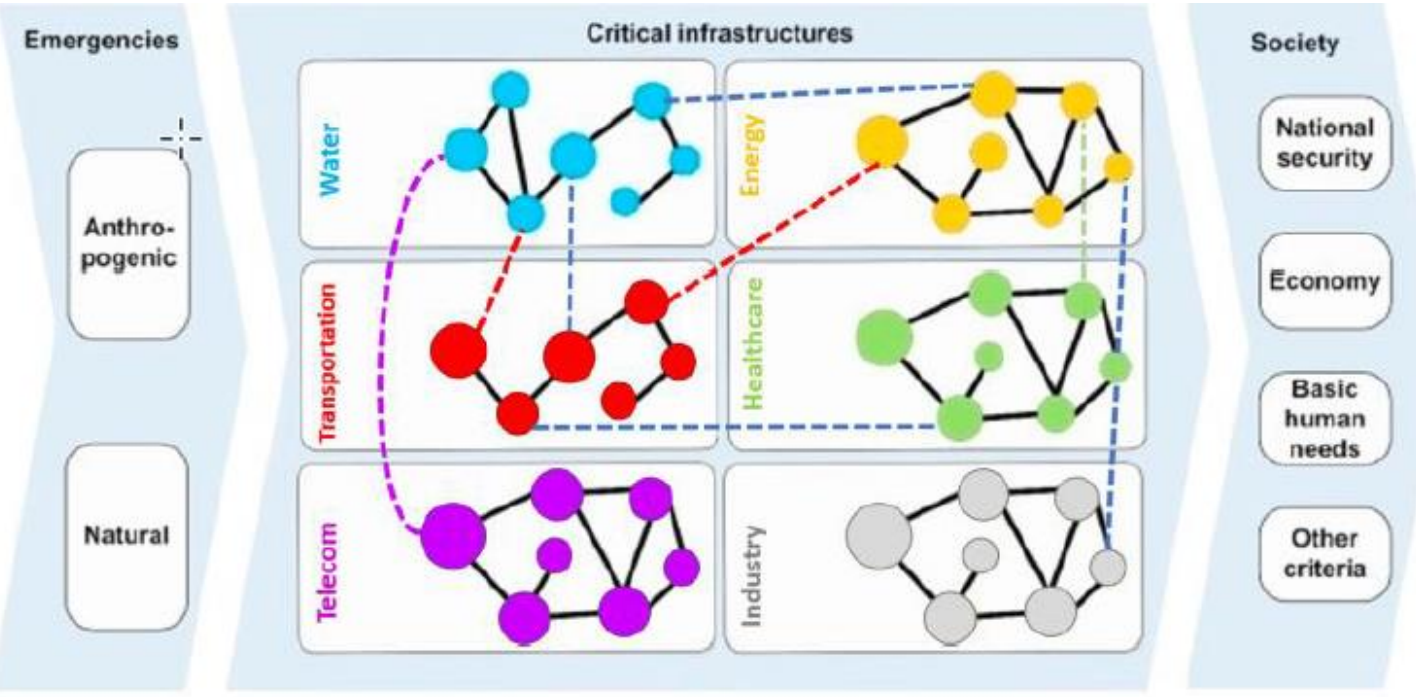

Figure 5. Framework proposed, where circles represent infrastructure element, full lines represent links among infrastructures, and dotted lines represent links among other infrastructures.

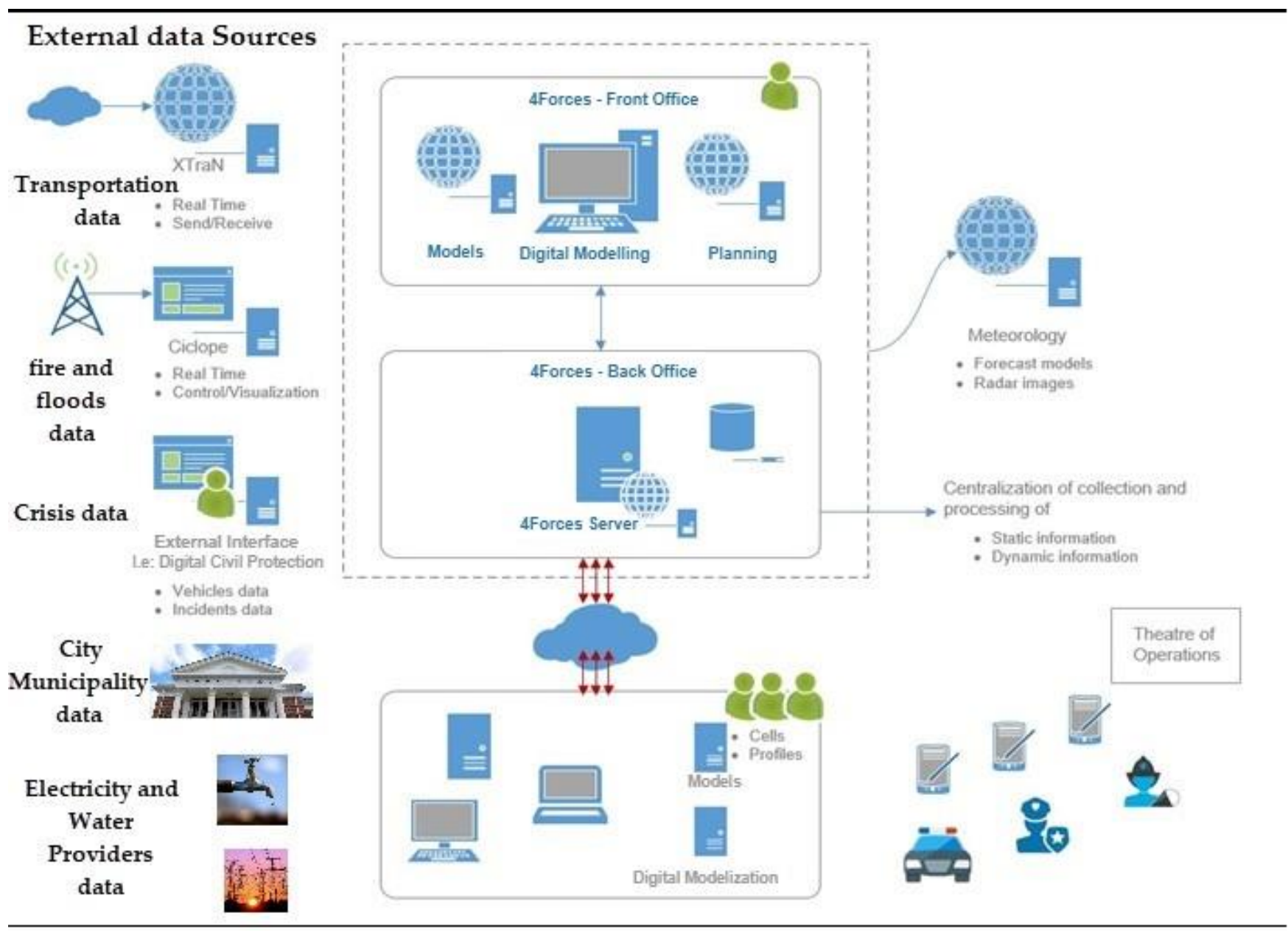

Figure 6. SC4Forces with XTraN tracking (professional Tecmic fleet management solution, for details https://www.tecmic. $\mathrm{com} / \mathrm{en} /$ tecmic-solutions / fleet-management/ (accessed on 18 May 2021)) product for first responders, external system interfaces, and a management platform for central command. 


\section{The Implementation of SCForces}

As referred, the implementation of the solution depends on the critical infrastructures involved and the data that are available at each of them. In an ideal solution, all necessary data would be available and in compatible format. This is not true in any situation, and several challenges need to be addressed. Addressing them requires the following sequence of steps:

1. Data Collection. This step is based on the hardware (HW) responsible for data collection, such as IoT sensors, mobile devices, radio-frequency identification (RFID) tags sensing, Global Positioning System (GPS), surveillance cameras, etc. Depending on the HW, the data can refer to location, orientation, image, noise, temperature, and humidity, among others. A diversity of data formats can be produced, such as Extensible Markup Language (XML), Comma-Separated Values (CSV), JavaScript Object Notation (JSON), Joint Photographic Experts Group (JPEG) digital image format, or Moving Picture Experts Group in version 2 (MPEG-2). Once collected, these data need to be sent to a previously defined location, which is completed in the next step.

2. Data Transmission. This step is responsible for connecting the data sources to the cloud, and transmission is based on a pre-defined set of communication protocols. Battery power devices use long-range low-power communication such as Long Range (LoRa) or Narrowband Internet of Things (NBIoT). Other HW-powered communication technologies can be included, such as Zigbee, Bluetooth, Wi-Fi, Ethernet, Worldwide Interoperability for Microwave Access (WiMax) Near-Field Communication (NFC), General Packet Radio Service (GPRS), 3G/LTE (Long-Term Evolution), and 5G. Once at the same location (at the cloud), data follow to the next step.

3. Data Integration. It is at this third step that the integration of data from heterogeneous sources (i.e., IoT sensors, social media streams, authoritative data in a data warehouse for later visualization or data analytics) is conducted. Non-structured data, such as social media data, are integrated based on Apache Flume (flume.apache.org). The Apache Sqoop (https:/ / sqoop.apache.org/) is responsible for extracting bulk data from structured databases, such as NoSQL (non-relational database). Spark Streaming (https://spark.apache.org/) can be used for real-time data collected from sources such as Twitter and IoT-based data streams.

4. Data Visualization. This step is mainly oriented to geographic information visualization (static or dynamic) on maps (see examples in Figure 7). It provides the visualization of the location of the entities and means of the operations theatre, real-time weather information, real-time video surveillance information, threat monitoring/math modelling, and 3D visualization based on Google Earth.

5. Data Analytics and Management. This last step is a combination of different frameworks like Hadoop Distributed File System (HDFS) and Spark. Along with an HDFS storage-based solution, libraries for processing and analysing big data are applied. Apache Spark (https:/ / spark.apache.org/ (accessed on 18.05.2021)) is a general computation engine for Hadoop that supports the processing of real-time data streams. An Application Programming Interface (API) supports various computer languages (i.e., Python, Scala, Java), assuring flexibility. A pre-defined process is created, with the intervention of the different stakeholders, to manage the control procedures. Early event detection using IoT data and social networks can be implemented, if needed, and pattern recognition based on machine learning algorithms allows one to detect the patterns of information from textual or spatial data sets, which is crucial for disaster management. This step includes a semantic engine that can be used for effective information management, i.e., for categorizing, searching, and extracting unstructured information. Multi-hazard risk analyses and cascading effects analyses can be conducted as a diversity of data is available. Considering multiple hazards simultaneously can help decision-makers in an urban area to prioritize risk management and climate adaptation actions. Comparing risks across hazards on a common 
and consistent basis, such as the value of property damage, allows identifying which hazards are associated with higher expected losses. One example of a multi-hazard study in damage to buildings that quantifies the damage resulting from a range of natural hazards can be found in [45]. As described, this step not only considers analytics for decision making but also includes the possibility to develop predictions of security risks and incidents, including the assessment of their implications on smart systems and infrastructure and cascading effects internal to the SCCI. A more detailed approach to the prediction process is provided in the following section.

Regarding the system, there is an Application and Support Services layer that consists of an interactive web-based application interface that provides information and a big picture for the command centre. A mobile app allows the central command to manage the crisis scenario increasing flexibility for the decision-makers. Additionally, and supporting the different steps, a set of collaborative risk assessment and mitigation tools needs to be used. These will support stakeholders to jointly refine threats and define/develop mitigation strategies for those threats, including the mitigation of the cascade effects.
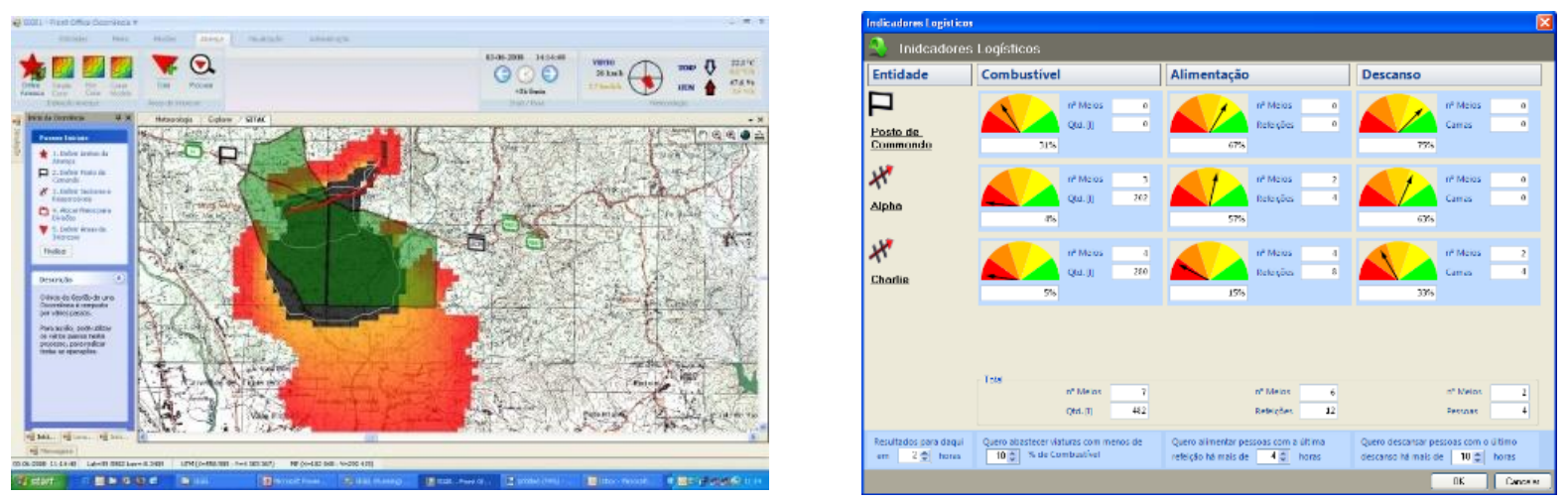

Figure 7. Examples of the data visualization process (example of situational awareness): on the left, a map with colour to indicate the severity of the hazard; on the right, data dashboards for monitoring purposes.

\section{Simulation and Prediction Process}

During a disaster, and even before that, in phases of analysis of vulnerabilities and development of mitigation and resilience strategies, simulation is required to understand the extension of the effects and their interconnections. The SC4Forces system includes a simulation environment as a basis to model critical infrastructures (transport, communication, energy distribution, water distribution, fire, floods, etc.), services (medical, mobility, public offices, etc.), safety aspects, and their cyber and physical backbones to predict the possible impact, response, and restoration scenario. A model of interdependencies between infrastructures is used to identify possible cascading effects. This model of interdependencies needs to be adjusted to each city. This module allows the development of contingency and mitigation plans, thus increasing the city's resilience.

Dedicated apps provide both real-time trust levels and real-time risk levels for guidance messages for citizens. Training and learning modules are available for both citizens and first responders.

The assessment of exposure, hazard, and risk mapping is traditionally seen as static (i.e., based on climatology or pre-defined scenarios) and procedures prior to the real disasters, providing important support and directions for the definition of effective contingency and mitigation plans.

The possibility of enriching and enhancing the same methodologies to better reflect the reality towards more holistic approaches in risk and hazard modelling is a valuable effort to improve strategic planning and prevent incidents.

This approach enables intelligent monitoring and continuous evolution of the systems, increasing situational awareness and tactical reaction and facilitating the possibility of 
defining alerts and alarms once the hazard and risk values exceed specific thresholds. The determination of these thresholds for each specific type of hazard is also important, and it must be defined based on end-user experience and assessment of historical data of the specific city.

\subsection{Simulation-Flood Hazards}

The operation and continuous operational modelling of flood hazards allow identifying the highest-risk areas at a regional and local level. The capacity to forecast the flood and its impacts is based on the use of meteorological forecasts obtained by numerical weather prediction (NWP) models and/or precipitation nowcasting models as input for fully distributed hydrological models that can provide the forecasted discharge in the river network. The limited area models (LAMs) are NWP models at high spatial-temporal resolution providing a reaction time that goes from 3 to $6 \mathrm{~h}$ up to $72 \mathrm{~h}$, while precipitation nowcasting provides a reaction time between 0 and $3 \mathrm{~h}$.

The high-resolution flood forecast is divided into:

(a) Regional forecasts where the LAMs are used as input for a fully distributed hydrological model-in this case, LAMs will be combined with remote sensing techniques (weather radars and satellites) and observations from local sensors (e.g., rain gauges). All these hydrometeorological inputs will be used to feed a fully distributed hydrological model. This will result in a product that will provide flood hazards with a longer reaction time $(24 \mathrm{~h})$ but at a regional scale.

(b) Local forecasts where the nowcasting models are used as input for a fully distributed hydrological model:

- In this case, once an emergency is detected, or the risk level is above a specific threshold, the nowcasting model output is combined with observations available through remote sensors (weather radars and satellites), the observations from local sensors (e.g., rain gauges), and other available local information about real impact observations (including crowdsourcing). All these hydrometeorological inputs are used to feed a fully distributed hydrological model. This will result in a product that will provide flood hazard warnings with a short reaction time (up to $3 \mathrm{~h}$ ) but at a local scale. Flood inundation maps will also be generated.

- Two hydrological fully distributed open-source models used MOHID Land developed by Action Modulers and Instituto Superior Técnico [54]. This redundant implementation will allow us to compare and integrate both models to reduce uncertainties. The regional meteorological forecasting service is made available by Tecmic.

\subsection{Prediction Process}

Among preparedness activities, model-based early warning systems allow one to organize at a local level and patrol and monitor highest-risk areas, preventing the floods or ignition of fires, and, in any case, allow one to significantly reduce the elapsed time following the detection of a wildfire, reducing damages.

In this context, the ability to predict such extreme conditions at least $24 \mathrm{~h}$ in advance allows defining common strategies to implement preparedness activities, alerting institutions and fire risk managers, and, in extreme situations, preventively position ground and aerial resources, if available, in highest-risk areas, dislocating them from the lower-risk areas. The pre-positioning of the ground and aerial resources allows reducing the reaction time, in case of fire ignition, reducing burned area and other damages, including loss of lives.

We are forecasting the likelihood of a fire ignition based on the vegetation from satellite imaging (with vegetation cover-vegetation index, which provides an estimation of chlorophyll activity and soil surface temperature, allowing a good estimation of evapotranspiration) and soil properties and on meteorological conditions. A cumulative water balance index would also be needed to study drought stress. This forecast is even more relevant in cities with extensive green areas. 
Efficient prevention protocols and, in general, the integrated management of wildfire risk need to be based on advanced information and communication technologies. This process allows managing territorial data, real-time meteorological observation and forecasts, and the output of suitable modules to predict natural risks. The system is web-based, and it is compliant with the INSPIRE directive. For this reason, is can ingest all territorial data available in a standard format. Weather forecast models provide weather forecasts on a daily basis. The modules are mainly aimed at the prediction of hydrogeological and forest fire risk.

A daily fire risk bulletin is generated daily. We use a module that is based on the Fine Fuel Moisture Code (FFMC) of the Canadian Fire Weather Index (cwfis.cfs.nrcan.gc.ca/ background/summary/fwi), which represents the reference model in EFFIS. The FFMC has been suitably adapted to the vegetation cover of the Mediterranean area. In addition to EFFIS, we created, at national scale, high-resolution static and dynamic information to better discriminate the highest-risk conditions. Geographic Information System and remote sensing technologies feed the system with static and dynamic information. The capacity to define a clear decision-making mechanism for implementing preparedness activities, considering that each country has minimal resources, is the main objective of this task.

These implementations are a complement to the European Forest Fire Information System (EFFIS (www.efas.eu [accessed on 18.05.2021])), as they aim to provide higherresolution forecasts than EFFIS outputs $(10 \mathrm{~km}$ or $16 \mathrm{~km})$, although at a local scale. We are working with a set of approaches for a diversity of disasters to perform real-time predictions.

\section{The Use Case of Lisbon}

The proposed system needs to be adjusted to each city. The case of the city of Lisbon, the capital of Portugal, is used to illustrate some of the system's features. Data integration and preparation took a three-year process (2017-2020) with data integration and cleaning processes.

The city of Lisbon has specific features that require special attention (other cities will also have specific features, their own features). Lisbon is a city by the river Tagus, close to the Atlantic Ocean. The city has several hills (seven), which create several challenges in terms of disaster management. As in any other city, there are areas with different characteristics. The main ones in Lisbon are:

- Downtown Lisbon is the city centre, one area with many buildings that were built after the 1755 earthquake and subsequent fires and others that are from before that period. The access routes in some places are narrow and curvy. The structure of the buildings is mostly made of wood. Buildings usually have three to four floors, and most of them have no elevators. The electrical systems of the older buildings have not been revised for several decades.

- $\quad$ Bairro Alto, Castelo, and other areas close to the castle are very old, narrow, curvy streets. Many buildings are from before the earthquake. Buildings are a mixture of wood and stone.

- The areas closer to the river and to the right of the downtown have similar characteristics to Bairro Alto and Castelo.

- Parque das Nações is the newest area of the city. It was projected and started to be built about 25 years ago. The planning respected the most modern regulations.

- The remaining areas are the result of the natural growth of the city, with buildings ranging from a few decades to close to two centuries of age. In many cases, the structure of the buildings is made from wood.

The city's emergency resources (vehicles and persons) management is challenging. Data integration and analytics from former incidents were performed based on data from the fire brigade, city incident report, transportation tracking data, and hospital data. The data used concerns 2019. The goal was to identify areas where there is a higher concentration of disasters and, from that, identify where occurrences are more likely to happen in the future. 
We represent the incidents in Lisbon reported to the local municipality using a heat map, as illustrated in Figure 8 (visualization-implemented approach). This figure shows the distribution of all occurrences by their location. From Figure 8, it is possible to perceive that these are concentrated in downtown Lisbon, Olaias, Parque das Nações, Lumiar, and Benfica. Heat maps are intuitive spatial data representation where different colours represent areas with different concentrations of points-showing overall shape and concentration trends [28]. From a technical perspective, it is a visualization of each point's impact areas, with additional summing up in areas that overlap. The colour gradient depicts the impact power at a specific stage. The map is appealing, easy to interpret, and the visualization is more understandable for non-cartographer users.
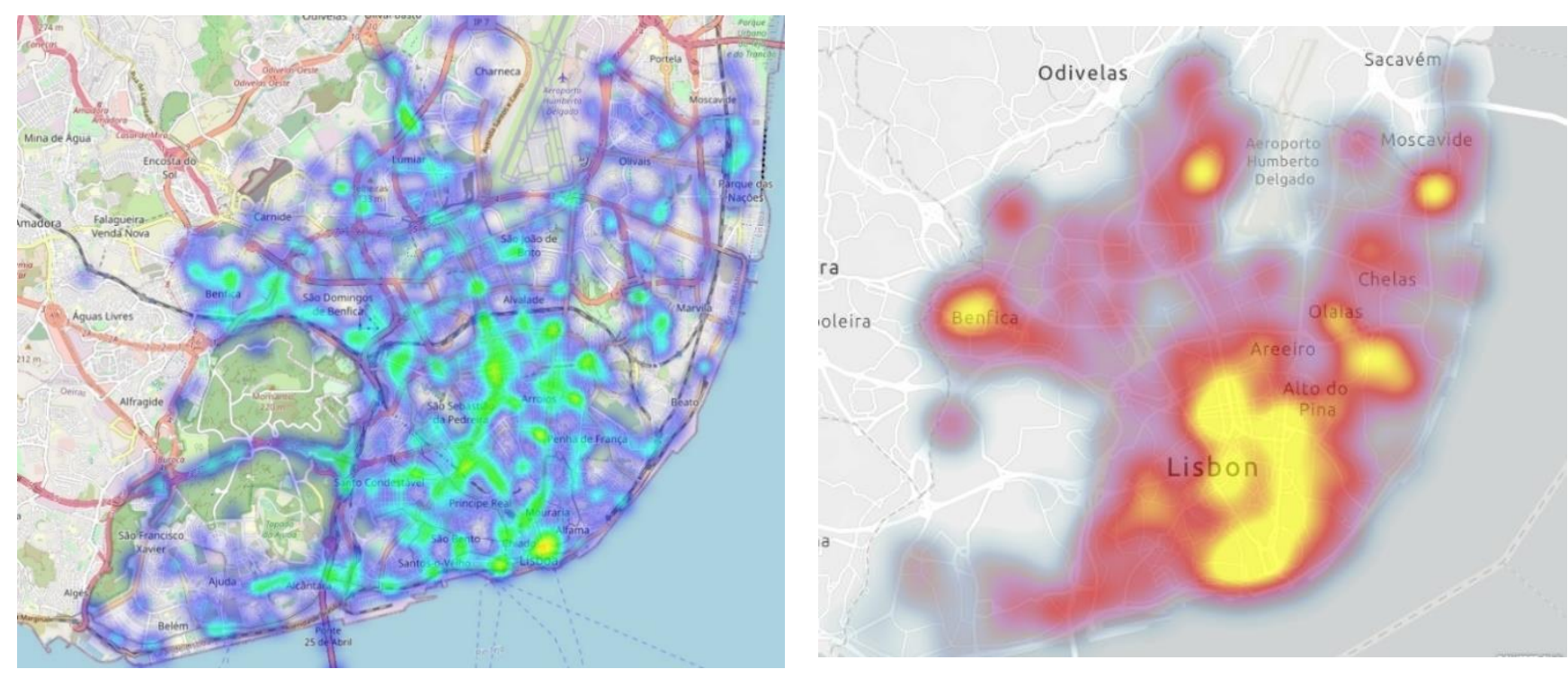

Figure 8. Heat map: distribution of incidents in the city of Lisbon; right data from fire brigade, where yellow colour represents the maximum number, and left from local municipalities for traffic. Colour from blue to green represents the intensity of the number of roads.

Overall, it is possible to conclude that disasters have a greater occurrence in downtown Lisbon, which is the area of Lisbon with a higher value of old buildings-it is the historical area of the city. In these areas, the streets are narrow. By identifying where (the areas of the city) disasters occur the most, critical incident managers have the possibility to pre-position the resources (such as the location of the intervention team and required materials and equipment) for a timelier response. The reduction of the response time allows limiting the expansion of the incident, which reduces the cascading effect.

Downtown Lisbon emerges as the most critical area of the city. Although other areas of the city also require preparedness, these areas have older and more fragile buildings, i.e., the buildings are more exposed to risk. Taskforces should always be prepared for interventions with appropriate vehicles and trained personnel. By identifying the most exposed areas and the characteristics of those areas, it is also possible to plan for the most adjusted equipment. A clear example is the size of the vehicles of the fire brigade. The older areas of the city, most exposed to fires and now identified as with a higher level of occurrences, require vehicles that are not as big as the conventional ones; otherwise, they would not fit those streets. The mechanical escalators for the firefighters also need to be of specific characteristics to fit the number of floors and the size of the streets. Another example is Parque das Nações, an area already with a firefighting system installed, wide streets, and buildings with many more floors: the type of firefighting equipment required, its location, and quantity needed can be adjusted based on the output of the data analysis of our proposed system. 
Although the example is based solely on historical data, it is already possible to conclude that the city's preparedness will improve, and by doing so, so will the city's resilience.

\section{Discussion}

The literature review showed that this is a new topic, with papers being published mainly from 2018. Although articles addressing disaster management were initially focused on natural disasters, there are several recent works approaching the city context. Nonetheless, the analysis of the cascading effects and predictions of scenario evolution is still lacking. The literature review shows that there are no articles yet addressing systems that use real-time data representation nor join different data sources in the context of a smart city. Due to the volume of data available, SC disaster management raises challenges in the possibility of considering this diversity and the possibility to account for the interdependencies in a cascading effect. Data, in a first approach, provide the big picture, and machine learning algorithms allow one to perform predictions considering current scenarios. Despite data integration complexity, there are advantages in data visualization and predictions to plan, absorb, recover, and adapt the city to the evolution of the disaster. Data integration required large efforts, and some approaches cannot be fully replicated in other cases because they depend on the specific characteristics of the system. This work used data from the fire brigade, local civil protection, national and local police (data regarding accidents), weather offices, public transportation office, energy suppliers, and water distribution offices. More connectors (data sources) could be considered, and in the future, if disaster data are stored with an appropriate description, they will allow the application of deep-learning algorithms, and consequently, better predictions can be produced.

Although the overall system needs to be adjusted to each case, the prediction algorithms and the simulation models considered in this case can be applied in other cases.

\section{Conclusions}

This research work aimed to improve the decision and management process in smart city critical network of infrastructures and its critical infrastructures to improve its resilience to the cascading effect of a disaster. Artificial intelligence was used to minimize such effects and was based on a set of data integrated from the different critical infrastructures and other entities in the city. The example of the city of Lisbon was used to illustrate the application of some components of the system. Data analytics and predictions will make cities safer, more secure, and resilient against physical threats and possible consequent cascade effects between the city's CIs network. We integrated and interoperated a proposed advanced solution in a local holistic platform (LHP), with a scalable and replicable approach, tested and validated by the city's local government. The various CIs and relevant LHP will be then federated to use the hub, seen as the central point of a connected and interdependent critical infrastructure ecosystem, as well as the entry point for providing many stakeholders to various services (such as to municipalities, CIs' owners and operators, citizens, and first responders).

Due to the missing standardization process among different systems, data integration is an arduous task, but once completed, data diversity is available to understand problems considering its interdependencies.

We tested our approach in the city of Lisbon to integrate data from different emergency systems, such as the fire brigade and its reports of incident problems.

The initial application of this proposal to Lisbon city showed that a big part of the occurrences is concentrated mainly in the city centre (the old area of the city) and Benfica area. Historical data about incidents showed to have good potential as they show patterns, allow predictions, and highlight the city's recurrent problems. The study of this data allows improvement in future city planning, and data integration among different systems creates a critical tendency, allowing this information to be used for future problems. By allowing a more adjusted response to an incident, it is possible to reduce the consequences of that incident and prevent a cascading effect on other subsystems of the city. Data mining can 
be used for incident management, and our application case showed that it is important to identify space and temporal patterns to manage these incidents in the city context.

Visualizing these data using a visualization process allows identifying the city's big picture and is an important tool for city incident management as it allows one to improve preparedness, produce a more adjusted response, and mitigate cascading effects. The prediction process allows better planning and improves the response time of intervention teams.

Data provided an integrated overview, but there is still much work to perform under the data integration task. Data analytics allows the generation of a big picture, and information can be used for decision support. The storage of these data and crisis scenario with evolution annotation will also allow the application of neural networks.

This research was based on a single city, and the specific conclusions are adjusted solely to the city of Lisbon. Nonetheless, the overall process can be replicated to other cities and adjusted to their specific characteristics. Future research should be conducted on this replication.

Data visualization in the case of the city of Lisbon allowed understanding patterns where disruptive events such as traffic or other accidents happen, and simulation and prediction process allow one to understand their evolution and prediction. Nonetheless, there is still more work needed in the process of simulating the cascading effects and KPI identification. These KPIs are important for assessing interdependencies because they have been used to evaluate two separate infrastructures under the same threat on numerous occasions. This paves the way for the framework to create a learning database of resilience indicators, allowing it to suggest indicators for a given assessment based on their use in previous assessments in similar scenarios. Still, much work is needed on data integration from different information sources, and it is mandatory to perform data analytics and entire problem interdependency. Evaluation of predictions in real scenarios will also improve this algorithm performance. This approach of considering any data available can be performed in any city. Taking into account Table 1, our work covered all dimensions, but we are still working on the development of cascading failures and infrastructure risk approaches.

Author Contributions: L.B.E. conducted all data mining processes, B.M.M. was responsible for system development, L.B.E. and A.L.M. wrote the state of the art, A.L.M. performed all the management interface and contributed to the writing of the article, and J.C.F. coordinated the research and contributed to the article's writing. All authors have read and agreed to the published version of the manuscript.

Funding: This research was funded by the Foundation for Science and Technology (FCT) through ISTAR-IUL's project UIDB/04466/2020 and UIDP/04466/2020.

Institutional Review Board Statement: Not applicable.

Informed Consent Statement: Not applicable.

Data Availability Statement: Not applicable.

Acknowledgments: J.C.F. received support from the Portuguese National Funds through FITECPrograma Interface, with reference CIT INOV_INESC INOVAÇÃO_Financiamento Base.

Conflicts of Interest: The authors declare no conflict of interest.

\section{References}

1. Musa, S. Smart cities-A roadmap for development. J. Telecommun. Syst. Manag. 2016, 5, 1-3.

2. United Nations Department of Economic and Social Affairs. 2018 Revision of World Urbanization Prospects, Multimedia Library. 2018. Available online: https://www.un.org/development/desa/publications/2018-revision-of-world-urbanization-prospects. html (accessed on 22 April 2021).

3. James, P.; Astoria, R.; Castor, T.; Hudspeth, C.; Olstinske, D.; Ward, J. Smart Cities: Fundamental Concepts. In Handbook of Smart Cities; Augusto, J.C., Ed.; Springer International Publishing: Cham, Switzerland, 2020; pp. 1-26.

4. Yaacoub, J.-P.A.; Salman, O.; Noura, H.N.; Kaaniche, N.; Chehab, A.; Malli, M. Cyber-physical systems security: Limitations, issues and future trends. Microprocess. Microsyst. 2020, 77, 103201. [CrossRef] 
5. Intergovernmental Panel on Climate Change. Managing the Risks of Extreme Events and Disasters to Advance Climate Change Adaptation. Special Report of Working Groups I and II of the Intergovernmental Panel on Climate Change; Field, C.B., Barros, V., Stocker, T.F., Dahe, Q., Eds.; Cambridge University Press: Cambridge, UK, 2012.

6. Qadir, J.; Ali, A.; Rasool, R.U.; Zwitter, A.; Sathiaseelan, A.; Crowcroft, J. Crisis analytics: Big data-driven crisis response. J. Int. Humanit. Action 2016, 1, 12. [CrossRef]

7. Mizrahi, S. Cascading disasters, information cascades and continuous time models of domino effects. Int. J. Disaster Risk Reduct. 2020, 49, 101672. [CrossRef] [PubMed]

8. Ashmore, F.H.; Farrington, J.H.; Skerratt, S. Community-led broadband in rural digital infrastructure development: Implications for resilience. J. Rural. Stud. 2017, 54, 408-425. [CrossRef]

9. Borsekova, K.; Nijkamp, P.; Guevara, P. Urban resilience patterns after an external shock: An exploratory study. Int. J. Disaster Risk Reduct. 2018, 31, 381-392. [CrossRef]

10. Costa, E.M.; Oliveira, Á.D. Humane smart cities. In The Oxford Handbook of Interdisciplinarity; Oxford University Press: Oxford, UK, 2017; pp. 228-240.

11. Barker, K.; Ramirez-Marquez, J.E. Infrastructure Network Resilience; EPFL International Risk Governance Center: Lausanne, Switzerland, 2016; p. 29.

12. Adger, W.N. Social and ecological resilience: Are they related? Prog. Hum. Geogr. 2000, 24, 347-364. [CrossRef]

13. Cutter, S.L.; Ahearn, J.A.; Amadei, B.; Crawford, P.; Eide, E.A.; Galloway, G.E.; Goodchild, M.F.; Kunreuther, H.C.; Li-Vollmer, M.; Schoch-Spana, M.; et al. Disaster Resilience: A National Imperative. Environ. Sci. Policy Sustain. Dev. 2013, 55, 25-29. [CrossRef]

14. GOV.UK. Keeping the Country Running: Natural Hazards and Infrastructure. Available online: https://www.gov.uk/ government/publications/keeping-the-country-running-natural-hazards-and-infrastructure (accessed on 6 September 2020).

15. Elvas, L.B.; Marreiros, C.F.; Dinis, J.M.; Pereira, M.C.; Martins, A.L.; Ferreira, J.C. Data-Driven Approach for Incident Management in a Smart City. Appl. Sci. 2020, 10, 8281. [CrossRef]

16. Korkali, M.; Veneman, J.G.; Tivnan, B.F.; Bagrow, J.P.; Hines, P.D.H. Reducing Cascading Failure Risk by Increasing Infrastructure Network Interdependence. Sci. Rep. 2017, 7, srep44499. [CrossRef]

17. Sun, W.; Bocchini, P.; Davison, B.D. Applications of artificial intelligence for disaster management. Nat. Hazards 2020, 103, 2631-2689. [CrossRef]

18. Fuggini, C.; Bolletta, F. Identification of indicators, metrics and level of service for the resilience of transport critical infrastructure. Int. J. Sustain. Mater. Struct. Syst. 2020, 4, 330. [CrossRef]

19. Cantelmi, R.; Di Gravio, G.; Patriarca, R. Reviewing qualitative research approaches in the context of critical infrastructure resilience. Environ. Syst. Decis. 2021, 41, 1-36. [CrossRef]

20. Lever, K.E.; Kifayat, K. Risk assessment and attack graph generation for collaborative infrastructures: A survey. Int. J. Crit. Comput. Syst. 2016, 6, 204. [CrossRef]

21. Ouyang, M. Critical location identification and vulnerability analysis of interdependent infrastructure systems under spatially localized attacks. Reliab. Eng. Syst. Saf. 2016, 154, 106-116. [CrossRef]

22. Dehghani, M.S.; Sherali, H.D. A resource allocation approach for managing critical network-based infrastructure systems. IIE Trans. 2016, 48, 826-837. [CrossRef]

23. Hosseini, S.; Barker, K. Modeling infrastructure resilience using Bayesian networks: A case study of inland waterway ports. Comput. Ind. Eng. 2016, 93, 252-266. [CrossRef]

24. Shafiee, M. Modelling and analysis of availability for critical interdependent infrastructures. Int. J. Risk Assess. Manag. 2016, 19, 299. [CrossRef]

25. Zimmerman, R.; Zhu, Q.; De Leon, F.; Guo, Z. Conceptual Modeling Framework to Integrate Resilient and Interdependent Infrastructure in Extreme Weather. J. Infrastruct. Syst. 2017, 23, 04017034. [CrossRef]

26. Bloomfield, R.E.; Popov, P.; Salako, K.; Stankovic, V.; Wright, D. Preliminary interdependency analysis: An approach to support critical-infrastructure risk-assessment. Reliab. Eng. Syst. Saf. 2017, 167, 198-217. [CrossRef]

27. Heracleous, C.; Kolios, P.; Panayiotou, C.G.; Ellinas, G.; Polycarpou, M.M. Hybrid systems modeling for critical infrastructures interdependency analysis. Reliab. Eng. Syst. Saf. 2017, 165, 89-101. [CrossRef]

28. Fotouhi, H.; Moryadee, S.; Miller-Hooks, E. Quantifying the resilience of an urban traffic-electric power coupled system. Reliab. Eng. Syst. Saf. 2017, 163, 79-94. [CrossRef]

29. Cheng, Q. A new mathematical framework and spatial decision support system for modeling cascade interdependency of critical infrastructure during geo-disasters. J. Earth Sci. 2017, 28, 131-146. [CrossRef]

30. Tweneboah-Koduah, S.; Buchanan, W.J. Security Risk Assessment of Critical Infrastructure Systems: A Comparative Study. Comput. J. 2018, 61, 1389-1406. [CrossRef]

31. Saidi, S.; Kattan, L.; Jayasinghe, P.; Hettiaratchi, P.; Taron, J. Integrated infrastructure systems-A review. Sustain. Cities Soc. 2018, 36, 1-11. [CrossRef]

32. McDonald, G.W.; Smith, N.J.; Kim, J.-H.; Brown, C.; Buxton, R.; Seville, E. Economic systems modelling of infrastructure interdependencies for an Alpine Fault earthquake in New Zealand. Civ. Eng. Environ. Syst. 2018, 35, 57-80. [CrossRef]

33. Lam, C.; Tai, K. Modeling infrastructure interdependencies by integrating network and fuzzy set theory. Int. J. Crit. Infrastruct. Prot. 2018, 22, 51-61. [CrossRef] 
34. Lu, L.; Wang, X.; Ouyang, Y.; Roningen, J.; Myers, N.; Calfas, G. Vulnerability of Interdependent Urban Infrastructure Networks: Equilibrium after Failure Propagation and Cascading Impacts. Comput. Civ. Infrastruct. Eng. 2018, 33, 300-315. [CrossRef]

35. Rand, K.; Fleming, C.H. An interdisciplinary review to develop guidelines for modeling population displacement as a function of infrastructure reconstruction decisions. Transp. Res. Interdiscip. Perspect. 2019, 3, 100072. [CrossRef]

36. Zheng, K.; Albert, L.A. A Robust Approach for Mitigating Risks in Cyber Supply Chains. Risk Anal. 2019, 39, $2076-2092$. [CrossRef]

37. Loggins, R.; Little, R.G.; Mitchell, J.; Sharkey, T.; Wallace, W.A. CRISIS: Modeling the Restoration of Interdependent Civil and Social Infrastructure Systems Following an Extreme Event. Nat. Hazards Rev. 2019, 20, 04019004. [CrossRef]

38. Sarker, P.; Lester, H.D. Post-Disaster Recovery Associations of Power Systems Dependent Critical Infrastructures. Infrastructures 2019, 4, 30. [CrossRef]

39. Thaduri, A.; Aljumaili, M.; Kour, R.; Karim, R. Cybersecurity for eMaintenance in railway infrastructure: Risks and consequences. Int. J. Syst. Assur. Eng. Manag. 2019, 10, 149-159. [CrossRef]

40. Iervolino, I.; Accardo, D.; Tirri, A.E.; Pio, G.; Salzano, E. Quantitative risk analysis for the Amerigo Vespucci (Florence, Italy) airport including domino effects. Saf. Sci. 2019, 113, 472-489. [CrossRef]

41. Karbowski, A.; Malinowski, K.; Szwaczyk, S.; Jaskóła, P. Critical Infrastructure Risk Assessment Using Markov Chain Model. J. Telecommun. Inf. Technol. 2019, 2, 15-20. [CrossRef]

42. Brown, C.; McDonald, G.; Uma, S.R.; Smith, N.; Sadashiva, V.; Buxton, R.; Grace, E.; Seville, E.; Daly, M. From physical disruption to community impact: Modelling a Wellington Fault earthquake. Australas. J. Disaster Trauma Stud. 2019, $23,65-75$.

43. Al-Zarooni, H.; Bashir, H. An integrated ISM fuzzy MICMAC approach for modeling and analyzing electrical power system network interdependencies. Int. J. Syst. Assur. Eng. Manag. 2020, 11, 1204-1226. [CrossRef]

44. Zhang, Y.; Najafi, M.R. Probabilistic Numerical Modeling of Compound Flooding Caused by Tropical Storm Matthew Over a Data-Scarce Coastal Environment. Water Resour. Res. 2020, 56, e2020WR028565. [CrossRef]

45. Sun, J.; Zhang, Z. A post-disaster resource allocation framework for improving resilience of interdependent infrastructure networks. Transp. Res. Part D Transp. Environ. 2020, 85, 102455. [CrossRef]

46. Hossain, N.U.I.; El Amrani, S.; Jaradat, R.; Marufuzzaman, M.; Buchanan, R.; Rinaudo, C.; Hamilton, M. Modeling and assessing interdependencies between critical infrastructures using Bayesian network: A case study of inland waterway port and surrounding supply chain network. Reliab. Eng. Syst. Saf. 2020, 198, 106898. [CrossRef]

47. Yang, Z.; Chen, Y.; Marti, J. Modelling cascading failure of a CPS for topological resilience enhancement. IET Smart Grid 2020, 3 , 207-215. [CrossRef]

48. Dong, S.; Wang, H.; Mostafizi, A.; Song, X. A network-of-networks percolation analysis of cascading failures in spatially co-located road-sewer infrastructure networks. Phys. A Stat. Mech. Appl. 2020, 538, 122971. [CrossRef]

49. Sharma, N.; Nocera, F.; Gardoni, P. Classification and mathematical modeling of infrastructure interdependencies. Sustain. Resilient Infrastruct. 2021, 6, 4-25. [CrossRef]

50. He, X.; Cha, E.J. DIN II: Incorporation of multi-level interdependencies and uncertainties for infrastructure system recovery modeling. Struct. Infrastruct. Eng. 2020, 16, 1-16. [CrossRef]

51. Sun, J.; Balakrishnan, S.; Zhang, Z. A resource allocation framework for predisaster resilience management of interdependent infrastructure networks. Built Environ. Proj. Asset Manag. 2021, 11, 284-303. [CrossRef]

52. Cardoni, A.; Cimellaro, G.; Domaneschi, M.; Sordo, S.; Mazza, A. Modeling the interdependency between buildings and the electrical distribution system for seismic resilience assessment. Int. J. Disaster Risk Reduct. 2020, 42, 101315. [CrossRef]

53. MOHID Studio-Quick-Start Guide for MOHID Land Implementation-Action Modulers Wiki. Available online: http://wiki. actionmodulers.com/wiki/index.php?title=MOHID_Studio_-_Quick-Start_Guide_for_MOHID_Land_Implementation (accessed on 12 September 2020).

54. Boné, J.; Ferreira, J.C.; Ribeiro, R.; Cadete, G. DisBot: A Portuguese Disaster Support Dynamic Knowledge Chatbot. Appl. Sci. 2020, 10, 9082. [CrossRef] 